\title{
Side-effects of high-dose fluticasone propionate in children
}

\section{To the Editor:}

EfTHIMIOU and BaRNes [1], in their review "Effect of inhaled corticosteroids on bones and growth", referred to our paper "Growth and adrenal suppression in asthmatic children treated with high dose fluticasone propionate" [2] as "anecdotal reports of growth deceleration in asthmatic children treated with inappropriately high doses (i.e. 5-10 times the recommended dose) of inhaled corticosteroids". In our study, the high doses were used as an alternative to oral corticosteroids in a group of children who had very severe asthma not controlled with lower doses of inhaled corticosteroids, short- and long-acting $\beta$-agonists and theophyllines. Frequent attempts were made to step down treatment if the asthma was stable. They should also be aware that the paper was not a study but a series of six case reports, and that case reporting is very important in new drug pharmacovigilance [3].

Fluticasone in doses of up to $1,000 \mu \mathrm{g} \cdot \mathrm{day}^{-1}$ (five times the recommended dose) is allowed by the British Thoracic Society guidelines (1995) for the treatment of asthma in children and P.J. Barnes himself has stated that "there is no convincing evidence that inhaled steroids even in high dose $\left(2 \mathrm{mg} \cdot\right.$ day $\left.^{-1}\right)$ have effects on ... growth in children" [4].

We conducted a survey of inhaled corticosteroid prescriptions in primary care and found that $>30 \%$ of all prescriptions for fluticasone are in excess of recommended doses and $4 \%$ for $\geq 1,000 \mu \mathrm{g} \cdot$ day $^{-1}$ (C. Fitzpatrick, personal communication). A survey of specialist paediatric centres in the UK showed that when high doses of inhaled corticosteroids $\left(>1,000 \mu \mathrm{g} \cdot \mathrm{day}^{-1}\right)$ are thought necessary, nearly all choose fluticasone proprionate (W. Lenny, personal communication). Thus, the usage of fluticasone proprionate in high doses in severely asthmatic children is common and not confined to our practice.

There are no long-term studies looking at this newest inhaled corticosteroid in high doses, hence the importance of our case reporting, which J. Efthimiou and P.J. Barnes underestimate.

All of our cases demonstrated that a very high first-pass hepatic metabolism (99.9\%) for fluticasone does not prevent the occurrence of serious systemic effects at high doses $\left(\geq 1,000 \mu \mathrm{g} \cdot \mathrm{day}^{-1}\right)$. This is probably due to the very high lipophilicity of fluticasone (250-300-times greater than beclomethasone or budesonide), which results in a much higher tissue distribution, longer plasma half-life and greater glucocorticoid receptor affinity than budesonide or beclamethasone [5]. Fluticasone is the only inhaled steroid reported to accumulate with repeated $>1,000 \mu \mathrm{g} \cdot$ day $^{-1}$ dosing in adults [6-11], although no accumulation effect has been detected with a dosage of $400 \mu \mathrm{g} \cdot$ day $^{-1}$ in children [12].

Therefore, there is also good pharmacokinetic evidence to support our clinical observations and these factors, in the absence of studies, should be taken into account when choosing an inhaled corticosteroid at a high dose in severely asthmatic children.

\section{G.R.G. Todd}

Consultant Chest Physician, Antrim Area Hospital, Antrim BT41 2RL, UK. Fax: 441849424679.

\section{References}

1. Efthimiou J, Barnes PJ. Effect of inhaled corticosteroids on bones and growth. Eur Respir J 1998; 11: 1167-1177.

2. Todd G, Dunlop K, McNaboe J, Ryan MF, Carson D, Shields MD. Growth and adrenal suppression in asthmatic children treated with high dose fluticasone propionate. Lancet 1996; 348: 27-29.

3. Bakke OM, Manocchia M, de Abajo F, Kaitin KI, Lasagna L. Drug safety discontinuations in the United Kingdom, the United States and Spain from 1974 through 1993: a regulatory perspective. Clin Pharmacol Ther 1995; 58: 108-117.

4. Barnes PJ. Inhaled glucocorticoids: new developments relevant to updating of the asthma management guidelines. Respir Med 1996; 90: 379-384.

5. Pederson $\mathrm{S}, \mathrm{O}^{\prime}$ Byrne P. A comparison of the efficacy and safety of inhaled corticosteroids in asthma. Allergy 1997; 52: Suppl. 39, 1-34.

6. Grahnen A, Eckermas SA, Brundin RM, Ling-Anderson A. An assessment of the systemic activity of single doses of inhaled fluticasone propionate in healthy volunteers. $\mathrm{Br}$ $J$ Clin Pharmacol 1994; 38: 521-525.

7. Lonnebo A, Connelo A, Grahnen A, et al. An assessment of the systemic effects of single and repeated doses of inhaled fluticasone propionate and inhaled budesonide in healthy volunteers. Eur J Clin Pharmacol 1996; 49: 459463.

8. Corren J, Rachelefsky G. A five-way randomised study to compare the safety profile of beclomethasone dipropionate (BDP), budesonide (BUD), flunisolide (FLU), fluticasone propionate (FP), and triamcinolone (TA) in healthy male volunteers. Chest 1996; 110: Suppl., 835.

9. Clark DJ, Lipworth BJ. Adrenal suppression with chronic dosing of fluticasone propionate compared with budesonide in adult asthmatic patients. Thorax 1997; 51: 55-58.

10. Falcoz C, Mackie AE, Moss J, et al. Pharmacokinetics of fluticasone propionate inhaled from the Diskhaler and the Diskus after repeat doses in healthy subjects and asthmatic patients. J Allergy Clin Immunol 1997; 99: S505.

11. Thorsson L, Dahlstrom K, Edsbacker S, Kallen A, Paulson J, Wirer J-E. Pharmacokinetics and systemic effects of inhaled fluticasone propionate in healthy subjects. $\mathrm{Br}$ Clin Pharmacol 1997; 43: 155-161.

12. Lipworth BJ, Clark DJ, McFarlane LC. Adrenocortical activity with repeated twice daily dosing of fluticasone propicasone propionate and budesonide given via a large volume spacer to asthmatic school-children. Thorax 1997; 52: 686-689. 


\section{REPLY}

\section{From the authors:}

Case reports such as those reported by TodD et al. [1] may be of some value in that they indicate that a few sensitive patients treated with high doses of inhaled steroids may experience a reduction in growth velocity. As stated in our review [2], identifying these patients, by means of their phenotypic and genotypic characteristics, may be key to managing paediatric asthma safely and optimally in the future.

The six case reports describe children receiving high doses (up to $>10$ times those recommended) of inhaled corticosteroids [1]. However, they provide only limited information on a number of key questions, namely: the control of the patients' asthma and the need for a change in treatment, their total corticosteroid exposure, the reason for the high doses of fluticasone propionate (FP) selected, the few height measurements and their precise timing with regard to both inhaled and oral corticosteroid therapy, details of other concurrent asthma medication and other diseases which could contribute to slowing of growth, the reason for continuing high doses of FP (up to 2,250 $\mu \mathrm{g} \cdot \mathrm{day}^{-1}$ ) for long periods and the lack of control patients, which have already largely been highlighted by others $[3,4]$. It seems very likely that the growth reduction reported in these cases may be equally explained by any or a combination of these other important clinical factors and not predominantly by FP as suggested in the article.

The case reports also need to be interpreted in the context of all the relevant major clinical trials in order to adequately assess the important risk-benefit balance of inhaled steroids in the treatment of children with asthma. At least three randomized, controlled studies have demonstrated that FP used at recommended doses up to 200 $\mu \mathrm{g} \cdot \mathrm{day}^{-1}$ for at least $1 \mathrm{yr}$ has no significant effect on growth velocity [5-7]. In addition, a further study in pre-pubertal children with asthma maintained on beclomethasone dipropionate (BDP) or budesonide in doses between 200 and $400 \mu \mathrm{g} \cdot \mathrm{day}^{-1}$, showed that when children with suppressed growth were changed to treatment with FP 100$200 \mu \mathrm{g} \cdot$ day $^{-1}$ for $1 \mathrm{yr}$, during which asthma control was well maintained, their mean height velocity standard deviation scores increased substantially (i.e. from -1.7 on BDP and -1.0 on budesonide, to +1.6 on FP) [8].

FP in doses up to $1,000 \mu \mathrm{g} \cdot \mathrm{day}^{-1}$ is recommended by the British Thoracic Society guidelines in children with severe asthma, who might otherwise require treatment with oral corticosteroids [9]. The observation that most respiratory paediatricians choose to use FP as opposed to other inhaled steroids, when high doses of inhaled steroids are necessary, lends further support to the relative confidence specialists have in prescribing FP in children with severe asthma, based on their own clinical experience. This confidence must also arise from the substantial number of large, randomized, controlled clinical trials which have demonstrated that FP is at least as or significantly more effective at half the milligram dose, with the same or significantly less systemic activity than BDP or budesonide, as recently summarized in a comparative meta-analysis [10].

The study by WHITAKER et al. [8] also confirms the 2:1 potency ratio of FP compared with BDP and budesonide and indicates that at therapeutically equivalent doses, if substituted for BDP or budesonide, FP may allow catch-up growth to occur in children with suppressed growth. At higher than currently recommended doses, bearing in mind the need for only half the daily milligram dose of FP compared with other inhaled steroids, there is no reason to expect otherwise. Indeed, a recently completed prospective, randomized study, comparing FP $400 \mu \mathrm{g} \cdot$ day $^{-1}$ with BDP $400 \mu \mathrm{g} \cdot \mathrm{day}^{-1}$ over $1 \mathrm{yr}$, in 342 moderate-to-severe asthmatic children requiring treatment with inhaled corticosteroids, demonstrated that growth velocity was significantly greater on FP, in addition to significantly better lung function control [11].

The low systemic activity of FP is related to both its high first-pass metabolism and its low oral absorption, leading to its very low oral bioavailability of $<1 \%$, which is substantially less than with other inhaled steroids [12]. The suggestion that FP accumulates after repeat dosing any more than any other inhaled steroid is neither pharmacokinetically consistent nor substantiated clinically. Although the terminal elimination half-life of FP is longer than other inhaled steroids, for equal amounts of drug absorbed, the resulting steady-state concentrations are likely to be very similar, consistent with the fact that the extent of accumulation is independent of the half-life of the drug and is only a function of clearance [13]. As G.R.G. Todd points out, no accumulation effect has been detected with FP at doses of $400 \mu \mathrm{g} \cdot \mathrm{day}^{-1}$ in children [14].

The only effective alternative to high-dose inhaled steroid therapy in children with severe asthma is frequent courses or maintenance therapy with oral corticosteroids, the systemic activity and effect on growth of which are likely to be substantially greater than therapeutically equivalent doses of inhaled steroids. With its high therapeutic ratio, FP currently offers one of the best risk-benefit options for the treatment of children with moderate-to-severe asthma, as confirmed by a number of randomized, controlled clinical studies $[11,15,16]$.

Currently the most reliable way of assessing the effect of inhaled steroids on growth in children is through welldesigned, carefully monitored, prospective studies, using standardized stadiometers and experienced staff, conducted over periods of at least $1 \mathrm{yr}$. Such data as they currently exist suggest that inhaled steroids at recommended doses have little if any effect on growth in children [2]. In addition, no effect on final height has been convincingly demonstrated with inhaled steroids and further appropriately designed studies, particularly with higher doses, are required to determine what, if any, this effect is. Inhaled steroids currently offer the best balance of risk-benefit ratio in the treatment of children with moderate-to-severe asthma, but the dose should be monitored closely with the aim of reducing this to the minimum required to provide effective control, with regular height measurements, bearing in mind that severe asthma itself can suppress growth. 


\section{J. Efthimiou}

GlaxoWellcome Research \& Development, Dept of Respiratory Medicine, Stockley Park, Middlesex UB11 1BT, UK. Fax: 441819908389.

\section{P.J. Barnes}

Dept of Respiratory Medicine, National Heart \& Lung Institute, London SW3 6LY, UK.

\section{References}

1. Todd G, Dunlop K, McNaboe J, Ryan MF, Carson D, Shields MD. Growth and adrenal suppression in asthmatic children treated with high dose fluticasone propionate. Lancet 1996; 348: 27-29.

2. Efthimiou J, Barnes PJ. Effect of inhaled corticosteroids on bones and growth. Eur Respir J 1998; 11: 1167-1177.

3. Cade A, Butler GE, Morrison JFJ, Chetcuti PJA. High dose inhaled steroids in asthmatic children. Lancet 1996; 348: 819.

4. Lenney W. High dose inhaled steroids in asthmatic children. Lancet 1996; 348: 819-820.

5. MacKenzie CA, Wales JKH. Clinical experience with inhaled fluticasone propionate-childhood growth. Am J Respir Crit Care Med 1994; 150: 351.

6. Konig O, Ford I, Galant S, et al. A 1-year comparison of the effects of inhaled fluticasone propionate and placebo on growth in prepubescent children with asthma. Eur Respir J 1996; 9: Suppl. 23, 294.

7. Price JF, Russell G, Hindmarsh PC, Weller P, Heaf DP, Williams J. Growth and one year treatment with fluticasone propionate or sodium cromoglycate in asthmatic children. Pediatr Pulmonol 1997; 24: 178-186.

8. Whitaker K, Webb J, Barnes J, Barnes ND. Effect of fluticasone on growth in children with asthma. Lancet 1996; 348: 63-64.

9. British Thoracic Society. The British guidelines on asthma management. Thorax 1997; 52: Suppl. 1, 1-21.

10. Barnes NC, Hallet C, Harris TAJ. Clinical experience with fluticasone propionate in asthma: a metaanalysis of efficacy and systemic activity compared with budesonide and beclomethasone dipropionate at half the microgram dose or less. Respir Med 1998; 92: 95-104.

11. Benedictis FM, Medley HV, Williams L. Long-term study to compare safety and efficacy of fluticasone propionate with beclomethasone dipropionate in asthmatic children. Eur Respir J 1998; 12: Suppl. 28, 142.

12. Falcoz C, Mackie A, MacDowell J, et al. Oral bioavailability of fluticasone propionate in healthy subjects. Br Clin Pharmacol 1996; 41: 459-460.

13. Derendorf H, Hochaus G, Meibohm B, Mollmann H, Barth J. Pharmacokinetics and pharmacodynamics of inhaled corticosteroids. J Allergy Clin Immunol 1998; 101: 440-446.

14. Thorsson L, Dahlstrom K, Edsbacker S, Kallen A, Paulson J, Wirer JE. Pharmacokinetics and systemic effects of inhaled fluticasone propionate in healthy subjects. Br Clin Pharmacol 1997; 43: 155-161.

15. Gustafsson P, Tsanakas J, Gold M, Primhak R, Radford M, Gillies E. Comparison of the efficacy and safety of inhaled fluticasone propionate $200 \mu \mathrm{g}$ /day with inhaled beclomethasone dipropionate $400 \mu \mathrm{g}$ in mild and moderate asthma. Arch Dis Child 1993; 69: 206-211.

16. Hoekx JCM, Hedlin G, Pedersen W, Sorva R, Hollingworth K, Efthimiou J. Fluticasone propionate compared with budesonide: a double-blind trial in asthmatic children using powder devices at a dosage of $400 \mu \mathrm{g} /$ day. Eur Respir J 1996; 9: 2263-2272. 